\title{
RELAÇÃO ENTRE O TEMPO DE ENRAIZAMENTO IN VITRO E O CRESCIMENTO DE PLANTAS DE BANANEIRA NA ACLIMATIZAÇÃ̃ ${ }^{1}$
}

\author{
FREDERICO HENRIQUE DA SILVA COSTA ${ }^{2}$, MOACIR PASQUAL ${ }^{3}$, JONNY EVERSON SCHERWINSKI PEREIRA ${ }^{4}$, \\ FILIPE ALMENDAGNA RODRIGUES ${ }^{5}$, LUZIA YURIKO MIYATA ${ }^{6}$
}

RESUMO - O trabalho objetivou avaliar a influência do tempo de permanência em meio de enraizamento sobre o crescimento in vitro e ex vitro de plantas de bananeira. Como explantes, foram utilizadas brotações axilares provenientes do estabelecimento e multiplicação in vitro de ápices caulinares das cultivares Caipira (AAA), Preciosa (AAAB) e Japira (AAAB). Para o enraizamento, empregou-se o meio MS reduzido a $50 \%$ da concentração de sais, adicionado de 30 g. $\mathrm{L}^{-1}$ de sacarose, $1 \mathrm{mg} . \mathrm{L}^{-1}$ de AIB e 6 g.L $\mathrm{L}^{-1}$ de ágar. Os tratamentos foram dispostos em esquema fatorial $3 \mathrm{x} 4$, com três cultivares (Caipira, Preciosa e Japira) e quatro períodos de enraizamento in vitro (7; 14; 21 e 28 dias), num total de 12 tratamentos. Ao final de cada período, a altura da parte aérea, o número e o comprimento de raízes foram avaliados, e as plantas, submetidas ao processo de aclimatização por 90 dias. Após esse período, as plantas foram avaliadas quanto à sobrevivência, número e comprimento de raízes, diâmetro do pseudocaule e massa seca de raízes, parte aérea e total. De modo geral, observou-se que a fase de indução de raízes nas brotações de bananeira in vitro ocorreu até os 14 dias de cultivo em meio de enraizamento, havendo apenas crescimento em tamanho das raízes após esse período. Entre as cultivares, verificou-se que, com exceção do diâmetro de pseudocaule, a cultivar Caipira apresentou crescimento vegetativo in vitro e durante a aclimatização (altura de plantas, número e comprimento de raízes e massa seca da parte aérea, raízes e total) superior às cultivares Preciosa e Japira. Após 21 dias de permanência em meio de enraizamento, a taxa de sobrevivência das plantas, observada em casa de vegetação, alcançou $100 \%$, independentemente da cultivar testada.

Termos para indexação: Musa spp., micropropagação, estabelecimento ex vitro, sistema radicular, genótipo.

\section{RELATIONSHIP BETWEEN THE IN VITRO ROOTING TIME AND THE GROWTH OF BANANA PLANTS IN THE ACLIMATIZATION}

ABSTRACT - The objective of the present study was to assess the influence of the exposition time to rooting medium on the in vitro and ex vitro growth of banana plants. As explants, new axillaries buds obtained from the in vitro establishment and multiplication of stem apices of Caipira (AAA), Preciosa (AAAB) and Japira (AAAB) cultivars were used. The MS medium with reduction to $50 \%$ of the salt concentration adding $30 \mathrm{~g} . \mathrm{L}^{-1}$ of sucrose, $1 \mathrm{mg} . \mathrm{L}^{-1}$ of IBA, and $6 \mathrm{~g} . \mathrm{L}^{-1}$ of agar was used to induce rooting. The treatments were analyzed in a $3 \times 4$ factorial design, with three cultivars (Caipira, Preciosa and Japira) and four in vitro rooting periods (7, 14, 21 and 28 days), given a total of 12 treatments. At the end of each period, the height of the aerial portion, and number and length of roots were assessed, and the plants were submitted to 90 days of acclimatization. After that, the survival, number and length of roots, pseudostem diameter, and dry weight of the roots, aerial and total portions of the plants were assessed. Generally, the root induction step in the in vitro banana budding occurred up to 14 days of cultivation in rooting medium, and after that, the roots grew only in length. Among the cultivars, it was verified that, with the exception of the pseudostem diameter, the Caipira cultivar showed superior in vitro vegetative growth, and during the acclimatization, the height of the plant, number and length of the roots, and dry mass of the aerial, roots, and total parts, were also superior to the observed in Preciosa and Japira cultivars. After 21 days on rooting medium, the survival rate of the plants in greenhouse reach $100 \%$, in despite of the tested cultivar.

Index terms: Musa spp.; micropropagation; ex vitro establishment; root system; genotype.

\section{INTRODUÇÃO}

A bananicultura é uma atividade de importância econômica e social em todo o mundo, sendo o Brasil o segundo produtor mundial, com cerca de 6,4 milhões de toneladas e área plantada de 508,5 mil hectares (Borges et al., 2006; Silva et al., 2006). No entanto, como para muitas espécies cultivadas em grandes áreas, a bananeira é afetada por diversos problemas fitossanitários, sendo a Sigatoka-negra, causada pelo fungo Mycospharella fijiensis Morelet, considerada a mais grave doença (Silva et al., 2003) e que tem ocasionado redução significativa na produção das cultivares Prata, Prata-Anã, Nanicão e Grande Naine, atualmente as mais difundidas e plantadas. Como conseqüência, foi criado, em 1982, o Programa

\footnotetext{
(Trabalho 078-07).Recebido em: 23-03-2007. Aceito para publicação em: 23-08-2007. Trabalho realizado com o apoio financeiro do Conselho Nacional de Desenvolvimento Científico e Tecnológico - CNPq.

${ }^{2}$ Eng. Agr ${ }^{\circ}$,Doutorando em Agronomia, UFLA, Caixa Postal 37, CEP 37200-000 Lavras-MG. E-mail: fredericohenrique@yahoo.com.br. Autor para correspondência. Bolsista do CNPq.

${ }^{3}$ Eng. Agr ${ }^{\circ}$,Professor do Departamento de Agricultura, UFLA, Lavras-MG. E-mail: mpasqual@ufla.br. Bolsista de Produtividade em Pesquisa do CNPq. ${ }^{4}$ Eng. Agr ${ }^{\circ}$,Pesquisador da Embrapa Recursos Genéticos e Biotecnologia, Caixa Postal 02372, CEP 70770-900, Brasília-DF. E-mail: jonny@cenargen.embrapa.br. Bolsista de Produtividade em Pesquisa do CNPq

${ }^{5,6}$ Graduando em Agronomia da Universidade Federal de Lavras, Lavras-MG
} 
de Melhoramento Genético da bananeira, coordenado pelo Centro Nacional de Pesquisa de Mandioca e Fruticultura Tropical, CNPMF/EMBRAPA, com os objetivos de introduzir e obter genótipos resistentes às principais doenças, produtivos e com frutos de qualidade, de onde se selecionaram as cultivares Caipira (AAA), Preciosa (AAAB) e Japira (AAAB).

Nesse contexto, a micropropagação de ápices caulinares e de meristemas constitui importante ferramenta para a rápida propagação clonal massal e validação de genótipos de bananeira recentemente lançados pelos programas de melhoramento genético (Gübbük \& Pekmezci, 2004; Rocha, 2005). Isso porque a produção de mudas utilizando métodos convencionais de propagação, além de se constituir num mecanismo de disseminação de doenças e pragas (Roels et al., 2005), apresenta baixa taxa de multiplicação, variando entre 3 e 10 filhotes por matriz/ciclo (Vuylsteke \& De Langhe, 1985), dependendo da cultivar e das condições de manejo da cultura.

Em geral, o processo de micropropagação da bananeira tem início a partir de um rigoroso processo de seleção de plantasmatrizes, seguido das fases de estabelecimento, multiplicação e enraizamento/alongamento in vitro, sendo as plantas obtidas submetidas à aclimatização em casa de vegetação ou telado. Destas etapas, o enraizamento/alongamento in vitro é considerado fundamental para a maioria das espécies, já que a obtenção de um sistema radicular funcional e uniforme é requisito básico para que se alcancem elevadas taxas de sobrevivência na fase de aclimatização. Entretanto, alguns pesquisadores suportam a hipótese de que a redução do período de enraizamento in vitro, ou mesmo sua eliminação, não prejudica a sobrevivência e o posterior desenvolvimento ex vitro de determinadas espécies (Preece \& Sutter, 1991; George, 1996; Grattapaglia \& Machado, 1998), contribuindo, dessa forma, para a redução significativa dos custos de produção e do tempo para a comercialização do material propagativo.

Assim, uma possível alternativa seria submeter as partes aéreas a uma fase de indução de raízes in vitro, seguida de uma etapa de alongamento em substrato (ex vitro), pois raízes mais curtas normalmente estão em fase de ativo crescimento, sendo mais adequadas ao transplante, por facilitar o manuseio, o pegamento e o posterior desenvolvimento ex vitro das plantas (Grattapaglia \& Machado, 1998; Woodhead \& Bird, 1998). Além disso, a maior permanência das plantas em meio de cultura pode proporcionar um rápido envelhecimento das raízes, tornando-as menos funcionais (Pereira \& Fortes, 2001), ao contrário do enraizamento ex vitro, que pode conferir qualidades adicionais ao sistema radicular formado (Debergh \& Read, 1991; Cuzzuol et al., 1996).

Diante do exposto, objetivou-se avaliar a influência do tempo de permanência em meio de enraizamento sobre o crescimento in vitro e ex vitro de plantas de bananeira.

\section{MATERIAL E MÉTODOS}

O trabalho foi conduzido no Laboratório de Cultura de Tecidos e Anexos do Departamento de Agricultura da Universidade Federal de Lavras, no município de Lavras, região sul do Estado de Minas Gerais, que, segundo KöPpen (1948), apresenta duas estações definidas: seca com temperaturas mais baixas, de abril a setembro, e chuvosa com temperaturas mais elevadas, de outubro a março. $\mathrm{O}$ experimento foi realizado entre os meses de maio e setembro de 2006.

O material vegetal utilizado foi constituído de brotações axilares (com cerca de $2 \mathrm{~cm}$ e desprovidas de raízes), provenientes do estabelecimento e multiplicação in vitro de ápices caulinares de bananeira das cultivares Caipira (AAA), Preciosa (AAAB) e Japira (AAAB), obtidas do banco ativo de germoplasma (BAG) da Embrapa Acre. O meio básico utilizado para a obtenção dos explantes foi o MS (Murashige \& Skoog, 1962), acrescido de 5 mg. $\mathrm{L}^{-1}$ de BAP, sendo os subcultivos realizados a cada 35 dias até obtenção de número suficiente de explantes para início do experimento.

Para o enraizamento in vitro, empregou-se o meio MS reduzido a $50 \%$ da concentração de sais, adicionado de 30 g. $\mathrm{L}^{-1}$ de sacarose e $1 \mathrm{mg} . \mathrm{L}^{-1}$ de ácido indolbutírico (AIB). Ambos os meios utilizados para a obtenção e enraizamento dos explantes foram solidificados com 6 g.L. $\mathrm{L}^{-1}$ de ágar $\left(\mathrm{Merse}^{\circledR}\right)$ e tiveram o $\mathrm{pH}$ ajustado para 5,8 $\pm 0,1$ antes da adição do agente geleificante, sendo em seguida autoclavados por 20 minutos, a $120^{\circ} \mathrm{C}$ e $1 \mathrm{~atm}$. Os tratamentos foram dispostos em esquema fatorial $3 \times 4$, constituído de três cultivares de bananeira (Caipira, Preciosa e Japira) e diferentes períodos de enraizamento in vitro $(7 ; 14 ; 21$ e 28 dias), num total de 12 tratamentos. O delineamento experimental utilizado foi inteiramente casualizado, com quatro repetições de quatro explantes cada, sendo os cultivos feitos em frascos de $250 \mathrm{~mL}$ contendo $40 \mathrm{~mL}$ de meio, selados com filme plástico transparente.

Uma vez estabelecidas, as culturas foram mantidas em sala de crescimento à temperatura de $25 \pm 2{ }^{\circ} \mathrm{C}$, fotoperíodo de 16 horas e irradiância de $42 \mathrm{~W} \cdot \mathrm{m}^{-2}$, fornecida por meio de lâmpadas fluorescentes tubulares do tipo luz do dia especial (OSRAM $20 \mathrm{~W}$ ). Ao final de cada período de cultivo in vitro, foram avaliados a altura da parte aérea e o número e o comprimento de raízes, sendo as plantas posteriormente submetidas à lavagem de suas raízes em água corrente, e imediatamente transferidas para tubetes de $0,3 \mathrm{~L}$ preenchidos com substrato composto de terra de subsolo (abaixo de $40 \mathrm{~cm}$ ): Plantmax Hortaliças $\mathrm{HT}^{\circledR}$ : casa de arroz carbonizada $(1: 1: 1 \mathrm{v} / \mathrm{v})$, acrescido de 50 g.L. $\mathrm{L}^{-1}$ dehúmus e $20 \mathrm{~g} . \mathrm{L}^{-1} \mathrm{de}$ supersimples. Em seguida, as plantas foram mantidas em casa de vegetação por 90 dias, cobertas com filme de polietileno transparente (150 microns), apresentando sombreamento de 70\% (Sombrence ${ }^{\circledR}$ ) e sistema de nebulização intermitente. A parcela experimental foi constituída de três plantas (uma por tubete), com cinco repetições por tratamento, num total de 15 plantas, em delineamento inteiramente casualizado.

Decorridos 90 dias da transferência para casa de vegetação, foram avaliados os seguintes parâmetros de crescimento: altura da parte aérea, diâmetro do pseudocaule, número e comprimento de raízes, além da massa seca de raízes (MS'R), parte aérea (MS'PA) e total (MS'T) das plantas, sendo a massa seca determinada após secagem em estufa a $60^{\circ} \mathrm{C}$, por $48 \mathrm{~h}$, até o peso constante. 
Os dados foram submetidos à análise de variância, utilizando o programa estatístico SANEST (Zonta \& Machado, 1984), e as médias, comparadas pelo teste de Tukey, a $5 \%$ de probabilidade. Na análise estatística, dados obtidos por contagem (x) foram transformados segundo $(x+0,5)^{0,5}$. A sobrevivência das plantas foi avaliada por simples observação visual e determinada pela razão entre o número de plantas desenvolvidas e o número total transferido para as condições ex vitro, não tendo sido analisadas estatisticamente.

\section{RESULTADOS E DISCUSSÃO}

\section{Enraizamento in vitro}

A interação entre os fatores estudados (cultivares e tempo de enraizamento) foi observada apenas para a altura da parte aérea, enquanto o efeito isolado dos fatores foi verificado para número e comprimento de raízes (Tabela 1).

Para número de raízes, a cultivar Caipira foi significativamente superior às demais, enquanto, em relação ao tempo de enraizamento, diferenças significativas somente foram observadas entre plantas cultivadas por 7 dias e aquelas enraizadas por 14; 21 e 28 dias. Quanto ao comprimento de raízes, incremento significativo foi verificado à medida que as plantas permaneceram em meio de cultivo, enquanto, entre as cultivares, somente a Caipira e a Preciosa diferiram $(P<0,05)$ (Tabela 1). Dessa forma, pode-se inferir que, após a fase de indução dos primórdios radiculares, não há mais emissão de raízes, mas, sim, o crescimento/alongamento destas, concordando com Grattapaglia \& Machado (1990) e Woodhead \& Bird (1998), segundo os quais, o processo de enraizamento in vitro constitui-se de três fases: indução, iniciação e alongamento, sendo a duração de cada fase compreendida entre 1 a 3 semanas, a depender da espécie e das condições de cultivo.

Resultados semelhantes foram obtidos por Molla et al. (2004), em bananeira da cultivar Bari, os quais evidenciaram maior número médio de raízes por explante com aumento do período de cultivo em meio de enraizamento in vitro, independentemente das concentrações de AIB estudadas. Adicionalmente, foi observado pouco incremento no número de raízes entre o $20^{\circ} \mathrm{e}$ $25^{\circ}$ dia de cultivo, com maior média ( 8,28 raízes) aos 35 dias de cultivo in vitro na presença de $0,5 \mathrm{mg} . \mathrm{L}^{-1}$ de AIB. Trabalhando com Musa sapientum cv. BARI-I, Rahman et al. (2004) também constataram incremento no número de raízes com o tempo de cultivo in vitro, embora a média obtida nesta espécie tenha sido relativamente baixa (2,83 raízes aos 30 dias de cultivo).

Com relação à altura da parte aérea, nenhuma diferença significativa entre as cultivares estudadas foi evidenciada aos 7 dias, indicando que os explantes utilizados neste estudo foram homogêneos, com média de $3 \mathrm{~cm}$. Analisando a interação, as diferentes cultivares tiveram repostas diferenciadas para cada tempo de enraizamento testado, embora a permanência das brotações por um maior período ( 28 dias) tenha promovido as maiores alturas. Essa especificidade de cada cultivar e as diferentes respostas obtidas neste trabalho podem ser atribuídas ao nível de oxidação observado na base dos explantes ainda nos primeiros dias após a inoculação, a qual foi mais expressiva nas cultivares Preciosa e Japira, grupo genômico AAAB, bem como a constituição genômica de cada genótipo. A oxidação verificada durante algumas das etapas do cultivo in vitro pode influenciar sobremaneira na absorção dos constituintes do meio pelo explante e, conseqüentemente, no crescimento destes em virtude da obstrução do tecido oxidado, resultante da liberação de compostos fenólicos in vitro, precursores da síntese de lignina pelo tecido injuriado (Oliveira et al., 2001; Van Winkle et al., 2003). Nesse mesmo sentido, trabalho conduzido por Costa et al. (2006) com a cultivar Grande Naine (AAA), durante a fase de multiplicação in vitro, demonstrou que a adição de $3 \mathrm{~g} . \mathrm{L}^{-1}$ de carvão ativado durante essa fase promove redução significativa do nível de oxidação, assim como a obtenção de brotações mais altas, vigorosas e com maior número de raízes.

De acordo com Hirimburegama \& Gamage (1997), cultivares portadoras do genoma B (Musa balbisiana) mostram maior escurecimento (oxidação) dos tecidos excisados ou cortados, comparadas àquelas apresentando apenas genoma $\mathrm{A}$ (Musa acuminata), sendo este escurecimento mais intenso aos 2 dias de inoculação. Além disso, entre os grupos genômicos avaliados, os autores constataram acima de $75 \%$ de escurecimento na superfície dos explantes para o grupo BB, 50$65 \%$ no $\mathrm{ABB}$, de $50-25 \%$ para o $\mathrm{AAB}$ e menos do que $25 \%$ para o AAA e AAAA. Diferenças entre genótipos de bananeira foram ainda observadas por Novak et al. (1990) para a massa fresca dos brotos, o que foi atribuído ao nível de ploidia e constituição genômica dos híbridos estudados. Nesse mesmo sentido, Gübbük \& Pekmezci (2004), avaliando cultivares pertencentes ao subgrupo Cavendish, grupo AAA, verificaram diferenças quanto ao comprimento de raízes e diâmetro do pseudocaule.

\section{Aclimatização}

O processo de aclimatização das plantas de bananeira micropropagadas apresentou, ao final de 90 dias, em casa de vegetação, sobrevivência acima de $80 \%$ em todas as cultivares estudadas. Perdas foram verificadas apenas para as cultivares Preciosa aos 7 dias e Japira aos 7 e 14 dias de cultivo em meio de enraizamento. Nessas condições, observou-se pouco desenvolvimento da parte aérea (muitas vezes apresentando apenas uma folha expandida) e rizoma pouco definido, com fraca iniciação de primórdios radiculares, sugerindo baixa quantidade de reservas para sustentarem seu crescimento ex vitro (Tabela 2).

Estudando os efeitos de concentrações de AIB na formação de raízes e na subseqüente transferência para condições ex vitro da bananeira cv. Bari, Molla et al. (2004), observaram de $95 \%$ a $100 \%$ de sobrevivência das plantas cultivadas por 15 e 20 dias em meio de cultura contendo entre 0,4 e $0,6 \mathrm{mg} . \mathrm{L}^{-1}$ de AIB e submetidas à pré-aclimatização, durante 7 dias, à temperatura ambiente. Por outro lado, plantas cultivadas in vitro por 5 dias não sobreviveram após o transplantio, independentemente da concentração de auxina estudada, enquanto plantas cultivadas por 10 dias tiveram entre $0 \%$ e $29,66 \%$ de sobrevivência, a qual aumentou com a concentração de AIB utilizada. Ainda, Bosa et al. (2003) observaram resposta linear crescente em relação à permanência em meio de enraizamento in vitro na sobrevivência ex vitro de Gypsophila 
paniculata, com $90 \%$ a $98 \%$ de sobrevivência, em plantas enraizadas por 5 a 30 dias, respectivamente. Assim, a maior taxa de sobrevivência, aos 30 dias, foi atribuído ao maior acúmulo de reservas nos tecidos, conferindo maior resistência às folhas.

Resultados positivos quanto ao menor período de permanência em meio de enraizamento foram também evidenciados por Pereira \& Fortes (2001), em que o transplante das brotações de macieira mantidas por 12; 15; 21 e 30 dias in vitro possibilitou sobrevivência média superior a $90 \%$, fato ainda reportado por Ribas (1991) com a cultivar de macieira Gala, clone FZ.

De acordo com Oliveira et al. (2001), brotos micropropagados de bananeira com tamanho inferior a $1,5 \mathrm{~cm}$ necessitam de maior período de alongamento em meio de enraizamento in vitro e são propensos a elevadas perdas durante a aclimatização. Além disso, o tipo de sistema radicular formado in vitro tem sido considerado um dos fatores determinantes do sucesso na sobrevivência das plantas após o transplantio, visto que raízes mais curtas são mais adequadas por se apresentarem em fase de crescimento ativo, facilitando a sobrevivência das plantas no momento da aclimatização (Grattaplagia \& Machado, 1990).

Acrescenta-se ainda que, embora existam trabalhos que reportem ser desejável a diminuição ou até mesmo a eliminação da etapa de enraizamento in vitro, devido ao aspecto econômico ou mesmo por causa de possíveis benefícios ao sistema radicular (Debergh \& Read, 1991; Pereira \& Fortes, 2001), os resultados obtidos no presente estudo demonstram que, para as cultivares de banana estudadas, a fase de enraizamento in vitro é necessária, principalmente se as brotações tiverem tamanho reduzido no momento do enraizamento. Entretanto, pode-se otimizar o tempo de enraizamento in vitro sem, contudo, haver perdas significativas de plantas, o que poderia possibilitar a redução dos gastos com energia e mão-de-obra, uma vez que a maior permanência das culturas na sala de crescimento incrementa os custos da muda micropropagada (Bosa et al., 2003).

Quanto ao número e comprimento de raízes, observou-se interação significativa entre os fatores, enquanto para a altura da parte aérea e o diâmetro do pseudocaule, os fatores influenciaram de modo isolado (Tabela 3). Assim, na cultivar Caipira, maior número de raízes foi verificado em plantas enraizadas in vitro, por 7 dias, embora diferenças significativas só tenham sido observadas em relação ao período de 28 dias. Por outro lado, nenhuma diferença foi evidenciada para comprimento de raízes neste genótipo $(P<0,05)$. Para a cultivar Preciosa, maior número e comprimento de raízes foi obtido em plantas cultivadas por 21 e 28 dias, enquanto para a cultivar Japira maior número e comprimento de raízes ocorreu aos 21 dias, embora não tenha diferido significativamente daquelas enraizadas por 14 e 28 dias (Tabela 3).

Experimentos realizados por Blomme \& Ortiz (2000) mostraram haver boa formação do sistema radicular em Musa, independentemente da idade das plantas micropropagadas, fato associado ao vigor e à elevada superfície foliar por elas apresentados. Porém, os autores verificaram diferenças em relação ao desenvolvimento do sistema radicular entre os grupos de Musa e tipos de propágulos (rebentos e micropropagados) testados, em que plantas micropropagadas nem sempre tiveram melhor sistema radicular. Em macieira, Pereira \& Fortes (2001) verificaram que, quanto menor o tempo de permanência das brotações em meio de enraizamento in vitro, menor é o tamanho do sistema radicular e da parte área dessas plantas em casa de vegetação, afetando, inclusive, o vigor das plantas.

Assim, de acordo com os resultados alcançados neste trabalho e em afirmações de Gribaudo et al. (1995), segundo os quais, as raízes formadas in vitro possuem substancial contribuição para o crescimento de videira durante a aclimatização, fica evidenciado o importante papel das raízes formadas in vitro. Ainda quanto ao enraizamento in vitro, Thomas \& Ravindra (1997) afirmam que a poda de raízes formadas in vitro proporciona maior facilidade no manejo e mais uniformidade no estande de plantas aclimatizadas de videira em comparação às plantas não-podadas, além de as plantas apresentarem rápido crescimento e melhor sistema radicular. Adicionalmente, estes autores observaram que, em experimento preliminar, plantascontrole contendo poucas raízes foram menos vigorosas, diferentemente daquelas com muitas raízes que apresentaram maior vigor após 4 semanas do transplantio.

Em relação à altura da parte aérea e diâmetro do pseudocaule, resultados superiores foram observados em plantas enraizadas in vitro por 21 e 28 dias, os quais diferiram dos 7 e 14 dias $(P<0,05)$, mostrando, assim, a importância de também se obterem plantas com parte aérea mais alongada (Tabela 3). Adicionalmente, avaliando-se os genótipos, a cultivar Caipira apresentou a maior altura de plantas $(P<0,05)$, o que se deve, muito provavelmente, ao fato de estas plantas terem tido maior crescimento in vitro em todos os tempos de enraizamento, favorecendo assim o conseqüente crescimento ex vitro. Para diâmetro do pseudocaule, as cultivares Preciosa e Japira foram significativamente superiores à Caipira.

Quanto à massa seca das plantas, cada cultivar foi influenciada de maneira distinta pelo tempo de permanência em meio de enraizamento in vitro, sendo que, para a cv. Caipira, maiores MS'R e MS'T foram verificadas aos 21 e 28 dias de cultivo, embora o tempo de 21 dias não tenha diferido significativamente do cultivo aos 7 dias para a MS'R. Por outro lado, maior MS'PA foi observada para brotações cultivadas por 21 dias. Efeitos semelhantes foram observados para a cultivar Japira, que apresentou maior MS'R quando as plantas foram submetidas a 21 e 28 dias de cultivo in vitro, sendo significativamente superiores aos demais tempos de permanência. Para a MS'PA e MS'T, a permanência das brotações por período de 21 dias possibilitou os melhores resultados. $\mathrm{Na}$ cultivar Preciosa, a permanência das brotações in vitro por um maior período (28 dias) promoveu os melhores resultados para a MS das plantas (Tabela 4).

Avaliando a possibilidade de redução do tempo de cultivo in vitro de bananeiras por meio da inoculação com fungo micorrízico, em diferentes estádios de enraizamento, Lins et al. (2003) observaram que a utilização de mudas em estádio intermediário e enraizadas apresentaram resultados superiores na produção de massa fresca e seca da parte aérea comparada às 
plantas não-enraizadas, independentemente da inoculação. Adicionalmente, foi observado que o uso de plantas enraizadas, inoculadas ou não, resultou em mudas com maior crescimento de raízes e radicelas no processo de aclimatização, levando os autores a concluir que plantas em estádio intermediário de enraizamento podem trazer mais benefícios ao seu posterior crescimento ex vitro, economizando tempo e espaço na formação das mudas.

Em estudo realizado com plantas micropropagadas de Gypsophila paniculata, Bosa et al. (2003) verificaram, aos 30 dias de aclimatização, aumento no volume de raízes para as plantas que permaneceram entre 15 e 25 dias sob enraizamento in vitro, não sendo mais verificado incremento significativo a partir daí. Em adição, maior acúmulo da massa seca das folhas foi observado nas plantas enraizadas por 15 e 20 dias, período acima do qual houve redução na taxa de crescimento, fato também obtido para massa seca de raízes. Nesse mesmo sentido, Pereira \& Fortes (2001) verificaram um comportamento linear ascendente quanto à matéria seca de plantas de macieira micropropagadas, tanto da parte aérea como das raízes, com o aumento do tempo de permanência das brotações em meio de enraizamento.

TABELA 1- Influência do tempo de enraizamento in vitro sobre o número e comprimento de raízes e altura da parte aérea de plantas de diferentes cultivares de bananeira, durante a fase de enraizamento in vitro. Lavras-MG, 2007.

\begin{tabular}{|c|c|c|c|c|}
\hline \multirow{2}{*}{$\begin{array}{l}\text { Tempo } \\
\text { (Dias) }\end{array}$} & \multicolumn{3}{|c|}{ Cultivares } & \multirow{2}{*}{ Médias } \\
\hline & Caipira & Preciosa & Japira & \\
\hline \multicolumn{5}{|c|}{ Número de raízes } \\
\hline 7 & 2,7 & 1,6 & 1,5 & $1,9 \mathrm{~b}$ \\
\hline 14 & 6,3 & 4,3 & 4,2 & $4,9 \mathrm{a}$ \\
\hline 21 & 6,4 & 4,3 & 4,2 & $5,0 \mathrm{a}$ \\
\hline 28 & 6,8 & 4,8 & 4,3 & $5,3 \mathrm{a}$ \\
\hline Médias & $5,5 \mathrm{~A}$ & $3,7 \mathrm{~B}$ & $3,5 \mathrm{~B}$ & \\
\hline C.V (\%) & & & & \\
\hline \multicolumn{5}{|c|}{ Comprimento de raízes $(\mathrm{cm})$} \\
\hline 7 & 0,0 & 0,0 & 0,0 & $0,0 \mathrm{~d}$ \\
\hline 14 & 3,5 & 1,9 & 1,9 & $2,4 \mathrm{c}$ \\
\hline 21 & 4,2 & 3,5 & 4,5 & $4,1 \mathrm{~b}$ \\
\hline 28 & 6,3 & 6,0 & 5,6 & $6,0 \mathrm{a}$ \\
\hline Médias & $3,5 \mathrm{~A}$ & $2,8 \mathrm{~B}$ & $3,0 \mathrm{AB}$ & \\
\hline C.V. (\%) & \multicolumn{4}{|c|}{25,2} \\
\hline \multicolumn{5}{|c|}{ Altura da parte aérea (cm) } \\
\hline 7 & $3,1 \mathrm{cA}$ & $3,1 \mathrm{bA}$ & $2,7 \mathrm{bA}$ & $3,0 \mathrm{c}$ \\
\hline 14 & $3,5 \mathrm{cA}$ & $3,1 \mathrm{bB}$ & $2,9 \mathrm{bAB}$ & $3,2 \mathrm{c}$ \\
\hline 21 & $4,7 \mathrm{bA}$ & $3,2 \mathrm{bB}$ & $4,0 \mathrm{aA}$ & $4,0 \mathrm{~b}$ \\
\hline 28 & $5,7 \mathrm{aA}$ & $4,9 \mathrm{aA}$ & $4,1 \mathrm{aB}$ & $4,9 \mathrm{a}$ \\
\hline Médias & $4,2 \mathrm{~A}$ & $3,6 \mathrm{~B}$ & $3,4 \mathrm{~B}$ & \\
\hline C.V. (\%) & & & & \\
\hline
\end{tabular}

Médias seguidas por letras distintas, minúsculas na vertical e maiúsculas na horizontal, diferem entre si, pelo teste de Tukey, a 5\% de probabilidade.

TABELA 2-Percentual de mortalidade de plantas micropropagadas de cultivares de bananeira sob o efeito do tempo de enraizamento in vitro, após 90 dias de aclimatização. Lavras-MG, 2007.

\begin{tabular}{ccccc}
\hline $\begin{array}{c}\text { Tempo } \\
\text { (Dias) }\end{array}$ & \multicolumn{3}{c}{ Cultivares } & \multirow{2}{*}{ Médias } \\
\cline { 2 - 4 } & Caipira & Preciosa & Japira & \\
\hline $\mathbf{7}$ & Percentual de mortalidade (sobrevivência ex vitro) & \\
\hline $\mathbf{1 4}$ & $0,0(100 \%)$ & $20,0(80 \%)$ & $13,0(87 \%)$ & $11,0(89 \%)$ \\
$\mathbf{2 1}$ & $0,0(100 \%)$ & $0,0(100 \%)$ & $7,0(93 \%)$ & $2,0(98 \%)$ \\
$\mathbf{2 8}$ & $0,0(100 \%)$ & $0,0(100 \%)$ & $0,0(100 \%)$ & $0,0(100 \%)$ \\
\hline Médias & $0,0(100 \%)$ & $0,0(100 \%)$ & $0,0(100 \%)$ & $0,0(100 \%)$ \\
\hline "Valores obtidos pela relação entre o número de plantas desenvolvidas e \\
número total de plantas transferidas.
\end{tabular}

TABELA 3 - Influência do tempo de enraizamento sobre o número (NR) e comprimento de raízes, altura da parte aérea e diâmetro do pseudocaule, em diferentes cultivares de bananeira, após 90 dias de aclimatização. Lavras-MG, 2007.

\begin{tabular}{|c|c|c|c|c|}
\hline \multirow{2}{*}{$\begin{array}{l}\text { Tempo } \\
\text { (Dias) }\end{array}$} & \multicolumn{3}{|c|}{ Cultivares } & \multirow{2}{*}{ Médias } \\
\hline & Caipira & Preciosa & Japira & \\
\hline \multicolumn{5}{|c|}{ Número de raízes } \\
\hline 7 & $8,0 \mathrm{aA}$ & $5,9 \mathrm{bcB}$ & $5,6 \mathrm{bB}$ & $6,5 \mathrm{ab}$ \\
\hline 14 & 7,0abA & $5,7 \mathrm{cB}$ & $6,5 \mathrm{abAB}$ & $6,3 \mathrm{~b}$ \\
\hline 21 & 7,3abA & 7,0abA & $7,1 \mathrm{aA}$ & $7,1 \mathrm{a}$ \\
\hline 28 & $6,4 \mathrm{bA}$ & $7,2 \mathrm{aA}$ & $6,5 \mathrm{abA}$ & $6,7 \mathrm{ab}$ \\
\hline Médias & $7,2 \mathrm{~A}$ & $6,4 \mathrm{~B}$ & $6,3 \mathrm{~B}$ & \\
\hline C.V (\%) & \multicolumn{4}{|c|}{4,9} \\
\hline \multicolumn{5}{|c|}{ Comprimento de raízes $(\mathrm{cm})$} \\
\hline 7 & $18,1 \mathrm{aA}$ & $11,6 \mathrm{cB}$ & $11,8 \mathrm{bB}$ & $13,8 \mathrm{~b}$ \\
\hline 14 & $18,7 \mathrm{aA}$ & $13,5 \mathrm{bcB}$ & $15,0 \mathrm{aB}$ & $15,7 b$ \\
\hline 21 & $18,4 \mathrm{aA}$ & $15,3 \mathrm{abB}$ & $16,2 \mathrm{aAB}$ & $16,6 \mathrm{a}$ \\
\hline 28 & $16,9 \mathrm{aA}$ & $16,3 \mathrm{aA}$ & $16,1 \mathrm{aA}$ & $16,4 \mathrm{a}$ \\
\hline Médias & $18,0 \mathrm{~A}$ & $14,2 \mathrm{~B}$ & $14,8 \mathrm{~B}$ & \\
\hline C.V. (\%) & \multicolumn{4}{|c|}{9,6} \\
\hline \multicolumn{5}{|c|}{ Altura da parte aérea $(\mathrm{cm})$} \\
\hline 7 & 11,8 & 9,9 & 9,2 & $10,3 b$ \\
\hline 14 & 11,8 & 9,3 & 10,9 & $10,7 b$ \\
\hline 21 & 16,8 & 13,7 & 14,4 & $15,0 \mathrm{a}$ \\
\hline 28 & 16,2 & 14,4 & 14,3 & $15,0 \mathrm{a}$ \\
\hline Médias & $14,1 \mathrm{~A}$ & $11,8 \mathrm{~B}$ & $12,2 \mathrm{~B}$ & \\
\hline C.V. (\%) & \multicolumn{4}{|c|}{8,2} \\
\hline \multicolumn{5}{|c|}{ Diâmetro do pseudocaule (cm) } \\
\hline 7 & 0,56 & 0,64 & 0,62 & $0,61 \mathrm{~b}$ \\
\hline 14 & 0,65 & 0,65 & 0,69 & $0,66 b$ \\
\hline 21 & 0,70 & 0,80 & 0,85 & $0,78 \mathrm{a}$ \\
\hline 28 & 0,72 & 0,82 & 0,77 & $0,77 \mathrm{a}$ \\
\hline Médias & $0,66 \mathrm{~B}$ & $0,73 \mathrm{~A}$ & $0,73 \mathrm{~A}$ & \\
\hline C.V. (\%) & \multicolumn{4}{|c|}{7,2} \\
\hline
\end{tabular}

Médias seguidas por letras distintas, minúsculas na vertical e maiúsculas na horizontal, diferem entre si, pelo teste de Tukey, a $5 \%$ de probabilidade.

TABELA 4 - Influência do período de enraizamento in vitro sobre a massa seca de raízes (MS'R), parte aérea (MS'PA) e total (MS'T) de diferentes cultivares de bananeira, após 90 dias de aclimatização. Lavras-MG, 2007.

\begin{tabular}{|c|c|c|c|c|}
\hline \multirow{2}{*}{$\begin{array}{c}\text { Tempo } \\
\text { (Dias) }\end{array}$} & \multicolumn{3}{|c|}{ Cultivares } & \multirow{2}{*}{ Médias } \\
\hline & Caipira & Preciosa & Japira & \\
\hline \multicolumn{5}{|c|}{ Massa seca de raízes (g) } \\
\hline 7 & $0,49 \mathrm{bA}$ & $0,18 \mathrm{cB}$ & $0,19 \mathrm{bB}$ & $0,29 \mathrm{c}$ \\
\hline 14 & $0,35 \mathrm{cA}$ & $0,22 \mathrm{cB}$ & $0,23 \mathrm{bB}$ & $0,27 \mathrm{c}$ \\
\hline 21 & $0,54 \mathrm{abA}$ & $0,35 \mathrm{bB}$ & $0,38 \mathrm{aB}$ & $0,42 b$ \\
\hline 28 & $0,65 \mathrm{aA}$ & $0,56 \mathrm{aA}$ & $0,42 \mathrm{aB}$ & $0,54 \mathrm{a}$ \\
\hline Médias & $0,51 \mathrm{~A}$ & $0,33 \mathrm{~B}$ & $0,30 \mathrm{~B}$ & \\
\hline C.V (\%) & \multicolumn{4}{|c|}{19,9} \\
\hline \multicolumn{5}{|c|}{ Massa seca de parte aérea (g) } \\
\hline 7 & $0,25 \mathrm{cA}$ & $0,17 \mathrm{bA}$ & $0,17 \mathrm{cA}$ & $0,20 \mathrm{c}$ \\
\hline 14 & $0,30 \mathrm{cA}$ & $0,23 \mathrm{bA}$ & $0,25 \mathrm{cA}$ & $0,26 \mathrm{c}$ \\
\hline 21 & $0,82 \mathrm{aA}$ & $0,50 \mathrm{aB}$ & $0,92 \mathrm{aA}$ & $0,75 \mathrm{a}$ \\
\hline 28 & $0,55 \mathrm{bA}$ & $0,56 \mathrm{aA}$ & $0,53 \mathrm{bA}$ & $0,55 \mathrm{~b}$ \\
\hline Médias & $0,48 \mathrm{~A}$ & $0,36 \mathrm{~B}$ & $0,47 \mathrm{~A}$ & \\
\hline C.V. $(\%)$ & \multicolumn{4}{|c|}{25,1} \\
\hline \multicolumn{5}{|c|}{ Massa seca total (g) } \\
\hline 7 & $0,70 \mathrm{bA}$ & $0,30 \mathrm{cB}$ & $0,40 \mathrm{cB}$ & $0,50 \mathrm{~b}$ \\
\hline 14 & $0,60 \mathrm{bA}$ & $0,44 \mathrm{cB}$ & $0,50 \mathrm{cAB}$ & $0,50 \mathrm{~b}$ \\
\hline 21 & $1,4 \mathrm{aA}$ & $0,85 \mathrm{bB}$ & $1,30 \mathrm{aA}$ & $1,2 \mathrm{a}$ \\
\hline 28 & $1,2 \mathrm{aA}$ & $1,1 \mathrm{aAB}$ & $0,94 \mathrm{bB}$ & $1,1 \mathrm{a}$ \\
\hline Médias & $0,97 \mathrm{~A}$ & $0,65 \mathrm{~B}$ & $0,77 \mathrm{~B}$ & \\
\hline C.V. $(\%)$ & \multicolumn{4}{|c|}{15,7} \\
\hline
\end{tabular}

Médias seguidas por letras distintas, minúsculas na vertical e maiúsculas na horizontal, diferem entre si, pelo teste de Tukey, a 5\% de probabilidade. 


\section{CONCLUSÕES}

1- Com exceção do diâmetro de pseudocaule, a cultivar Caipira apresentou crescimento vegetativo in vitro e ex vitro (altura de plantas, número e comprimento de raízes e massa seca da parte aérea e radicular) superior às cultivares Preciosa e Japira.

2- A fase de indução de raízes em brotações de bananeira in vitro ocorreu até os 14 dias de cultivo em meio de enraizamento, sendo que, após esse período, houve apenas o crescimento em tamanho das raízes.

3- O crescimento em altura das plantas é diretamente proporcional ao tempo de permanência das brotações em meio de enraizamento in vitro.

4 - A sobrevivência de plantas de bananeira em casa de vegetação atingiu $100 \%$ após 21 dias de cultivo em meio de enraizamento.

\section{AGRADECIMENTOS}

Ao Conselho Nacional de Desenvolvimento Científico e Tecnológico (CNPq), pela concessão das bolsas de estudos. À Embrapa Acre, pelo material vegetal utilizado.

\section{REFERÊNCIAS}

BLOMME, G.; ORTIZ, R. Preliminary assessment of root systems morphology in Musa. Acta Horticulturae, Amsterdam, v. 540, p. 259-266, 2000.

BORGES, A. L.; SILVA, S. de O. e; CALDAS, R. C.; LEDO, C. A. da $\mathrm{S}$. Teores foliares de nutrientes em genótipos de bananeira. Revista Brasileira de Fruticultura, Jaboticabal, v. 28, n. 2, p. 314-318, 2006

BOSA, N.; CALVETE, E. O.; NIENOW, A. A.; SUZIN, M.; Enraizamento e aclimatização de plantas micropropagadas de gipsofila. Horticultura Brasileira, Brasília, v. 21, n. 2, p. 207-210, 2003.

COSTA, F. H. da S.; PEREIRA, J. E. S.; PEREIRA, M. A. A.; OLIVEIRA, J. P. de. Efeito da interação entre carvão ativado e N6-benzilaminopurina na propagação in vitro de bananeira, cv. Grande Naine (AAA). Revista Brasileira de Fruticultura, Jaboticabal, v. 28, n. 2, p. 280-283, ago. 2006.

CUZZUOL, G. R. F.; GALLO, L.A.; CROCOMO, O. J. Enraizamento de cravo (Dianthus caryophyllus L.) in vitro e ex vitro. Scientia Agrícola, Piracicaba, v. 53, n. 1, p. 60. 66, 1996.

DEBERGH, P. C.; READ, P. E. Micropropagation. In: DEBERGH, P. C.; ZIMMERMAN, R. H. (Ed.). Micropropagation: technology and application. Amsterdan: Kluwer Academic, 1991. p. 1-13

GEORGE, E. F. Plant propagation by tissue culture. $2^{\text {nd }}$ ed. Edington: Exegetics, 1996. 1361 p.
GRATTAPAGLIA, D.; MACHADO, M. A. Micropropagação. In: TORRES, A. C.; CALDAS, L. S. (Ed.). Técnicas e aplicações da cultura de tecidos de plantas. Brasília: ABCTP/Embrapa CNPH, 1990. p. 99-169.

GRATTAPAGLIA, D.; MACHADO, M. A. Micropropagação. In: TORRES, A. C.; CALDAS, L. S.; BUSO, J. A. (Ed.). Cultura de tecidos e transformação genética de plantas. Brasília: EmbrapaSPI, 1998. p. 183-260.

GRIBAUDO, I.; MORTE, M. A.; SCHUBERT, A. Use of gentian Violet to diffentiate in vitro and ex vitro formed roots during acclimatization of grapevine. Plant Cell Tissue and Organ Culture, Dordrecht, v. 41, n. 2, p. 187-188, 1995.

GÜBBÜK, H.; PEKMEZCI, M. In vitro propagation of some new banana types (Musa spp.). Turkish Journal of Agriculture and Forestry, Ankara, v. 28, p. 355-361, 2004.

HIRIMBUREGAMA, K.; GAMAGE, N. Cultivar specificity with respect to in vitro micropropagation of Musa spp. (banana and plantain). Journal of Horticultural Science, Ashford, v. 72, n. 2, p. 205-211, 1997.

KÖPPEN, W. Climatología: con un estúdio de los climas de la tierra. Mexico: Fondo de Cultura Economica, 1948. 478 p.

LINS, G. M. de L.; TRINDADE, A. V.; ROCHA, H. S. Utilização de Gigaspora margarita em plantas micropropagadas de bananeira em diferentes estádios de enraizamento. Revista Brasileira de Fruticultura, Jaboticabal, v. 25, n. 1, p. 143-147, 2003.

MOLLA, M. M. H.; KHANAM, M. D.; KHATUN, M. M.; ALAMIN, M.; MALEK, M. A. In vitro rooting and ex vitro plantlet establishment of BARI banana 1 (Musa sp.) as influenced by different concentration of IBA (indole 3-butyric acid). Asian Journal of Plant Sciences, Bholakpur, v. 3, n. 2, p. 196-199, 2004.

MURASHIGE, T.; SKOOG F. A. Revised medium for rapid growth and bio assays with tobacco tissue cultures. Physiologia Plantarum, Copenhagem, v. 15, n. 3, p. 473-497, 1962.

NOVAK, F. J.; AFZA, R.; VAN DUREN, M.; OMAR, M. S. Mutation induction by gamma irradiation of in vitro cultured shoot tips of banana and plantains (Musa cvs.). Tropical Agriculture, Trinidade, v. 67, n. 1, p. 21-28, 1990.

OLIVEIRA, R. P. de; SILVEIRA, D. G.; SILVA, S. de O. Concentração de BAP e a eficiência de micropropagação de bananeira tetraplóide (grupo AAAB). Scientia Agrícola, Piracicaba, v. 58, n. 1, p. 73-78, jan./mar. 2001.

PEREIRA, J. E. S.; FORTES, G. R. de L. Multiplicação e aclimatização da macieira influenciada pelo tipo de explante e pelo tempo de permanência em meio de cultura de enraizamento. Revista Brasileira de Fruticultura, Jaboticabal, v. 23, n. 2, p. 417-420, 2001. 
PREECE, J. E.; SUTTER, E. G. Acclimatization of micropropagated plants to the greenhouse and field. In: DEBERGH, P. C.; ZIMMERMAN, R. H. Micropropagation: technology and application. Amsterdan: Kluwer Academic Publishing, 1991. cap. 5, p. 71-93.

RAHMAN, M. Z.; NASIRUDDIN, K. M.; AMIN, M. A.; ISLAM, $M$. N. In vitro response and shoot multiplication of banana with BAP and NAA. Asian Journal of Plant Sciences, Bholakpur, v. 3, n. 4, p. 406-409, 2004.

RIBAS, L. L. F. Micropropagação e estudo da parada de crescimento durante a aclimatização de mudas de macieira (Malus domestica Borkh.) cv. Gala, clone FZ. 1991. 142 f. Dissertação (Mestrado) - Universidade Federal do Paraná, Curitiba, 1991.

ROCHA, H. S. Luz e sacarose na micropropagação da bananeira "Prata-Anã": alterações morfoanatômicas. 2005. 98 f. Dissertação (Mestrado em Fitotecnia) - Universidade Federal de Lavras, Lavras-MG, 2005.

ROELS, S.; ESCALONA, M.; CEJAS, I.; NOCEDA, C.; RODRIGUEZ, R.; CANAL, M.J.; SANDOVAL, J.; DEBERGH, P. Optimization of plantain (Musa AAB) micropropagation by temporary immersion system. Plant Cell, Tissue and Organ Culture, Dordrecht, v. 82, p. 57-66, 2005.

SILVA, E. A. da; BOLIANI, A. C.; CORRÊA, L. de S. Avaliação de cultivares de bananeira (Musa sp) na região de Selvíria-MS. Revista Brasileira de Fruticultura, Jaboticabal, v. 28, n. 1, p. 101-103, 2006.
SILVA, S. de O. e; GASPAROTTO, L.; MATOS, A. P. de; CORDEIRO, Z. J. M.; FERREIRA, C. F.; RAMOS, M. M.; JESUS, O. N. de. Programa de melhoramento de bananeira no Brasil: resultados recentes. Cruz das Almas: Embrapa Mandioca e Fruticultura, 2003.36 p. (Documentos, 123).

THOMAS, P.; RAVINDRA, M. B. Effect of pruning or removal of in vitro formed roots on ex vitro rot regeneration and growth in micropropagated grapes. Plant Cell, Tissue and Organ Culture, Dordrecht, v. 51, n. 3, p. 177-180, 1997.

VAN WINKLE, S.; JOHNSON, S.; PULLMAN, G. S. The impact of gelrite and activated carbon on the elemental composition of plant tissue culture media. Plant Cell Reports, New York, v. 21, n. 12, p. 1175-1182, 2003.

VUYLSTEKE, D.; DE LANGHE, E. Feasibility of in vitro propagation of bananas and plantains. Tropical Agriculture, Trinidad, v. 62, n. 4, p. 323-328, 1985.

WOODHEAD, J. L.; BIRD, K. T. Efficient rooting and acclimation of micropropagated Ruppia maritima Loisel. Journal of Marine Biotechnology, New York, v. 6, n. 3, p. 152-156, 1998.

ZONTA, E. P.; MACHADO, A. A. SANEST - Sistema de análise estatística para microcomputadores. Pelotas: UFPel, SEI, 1984. $138 \mathrm{p}$. 